\title{
Laparoscopic Heller Myotomy: A Fundoplication Is Necessary to Control Gastroesophageal Reflux
}

\author{
Marco Di Corpo, MD, ${ }^{1}$ Timothy M. Farrell, MD, and Marco G. Patti, MD, FACS ${ }^{1,2}$
}

\begin{abstract}
Background: Achalasia is a rare esophageal motility disorder that causes progressive dysphagia and regurgitation. The aim of treatment for achalasia is to provide symptom relief by reducing esophageal outflow resistance by disrupting the muscles at the level of the esophagogastric junction to allow esophageal emptying by gravity. Methods: A review of the literature concerning laparoscopic treatment of esophageal achalasia.

Results: Surgical myotomy with partial fundoplication is very effective in relieving symptoms, and is able to strike a balance between relief of symptoms and control of abnormal reflux.

Conclusions: Since reflux of gastric contents into the aperistaltic esophagus can cause esophagitis, peptic strictures, Barrett's esophagus, and even esophageal carcinoma, the addition of a partial fundoplication is very important. The choice of partial fundoplication is based on surgeons' preference and expertise.
\end{abstract}

Keywords: achalasia, dysphagia, gastroesophageal reflux, Heller myotomy, Toupet fundoplication, Dor fundoplication

\section{Introduction}

A CHALASIA IS A RARE esophageal motility disorder with a traditionally reported incidence of 1 per 100,000 individuals. ${ }^{1}$ However, the latest data have shown an incidence at least two to three times greater than previous studies. ${ }^{2}$ The incidence increases with age, and has an equal distribution across gender and race. $1,3,4$

Achalasia affects the esophageal smooth muscle layer, causing absent or spastic peristalsis, and absent or partial lower esophageal sphincter (LES) relaxation with an increased LES tone. ${ }^{5,6}$ The most common form of achalasia is idiopathic. $^{7,8}$ The pathophysiology of achalasia is due to a defect on the esophageal myenteric plexus (Auerbach's plexus) that contains parasympathetic and sympathetic fibers and supplies both the circular and longitudinal muscle layers with motor innervation. Because of a degeneration on the inhibitory nerves, both esophageal peristalsis and LES relaxation are severely affected. ${ }^{9}$ Owing to this lack of peristalsis and the nonrelaxing LES status, esophageal clearance is affected and patients with long-term achalasia may present with dilatated esophagus and loss of the normal organ axis. ${ }^{10}$ Consequently, food passage through the gastroesophageal junction (GEJ) may be defective, leading to the main esophageal symptoms: dysphagia, regurgitation, and heartburn. ${ }^{1}$ Moreover, despite there being evidence of an increasing incidence of esophageal squamous cell carcinoma in achalasia patients compared with the general population, the absolute risk still remains low. ${ }^{11}$ In contrast, patients who have a myotomy as treatment may develop postoperative gastroesophageal reflux (GER), with the risk of Barret's esophagus and esophageal adenocarcinoma. ${ }^{12}$

Therapy focuses on decreasing the outflow resistance of the GEJ caused by the dysfunctional LES. Medical treatment with drugs as nitrates and calcium channel blockers for muscle relaxation, ${ }^{13}$ or endoscopic sphincteric injection of botulin toxin, has limited effect. ${ }^{14}$ In contrast, pneumatic dilatation (PD) and endoscopic or surgical myotomy are the modalities most commonly used. ${ }^{3,15}$

There is evidence about the superior long-term outcomes for laparoscopic Heller myotomy (LHM) as compared with medical therapy and PD. ${ }^{16-19}$ Recently, LHM was described by Patti et al. ${ }^{6,20}$ as the gold standard therapy for most esophageal achalasia patients. Moreover, LHM is proposed by the SAGES guidelines as a safe and low-risk procedure for controlling dysphagia and improving quality of life $(\mathrm{QoL})$ in

Department of ${ }^{1}$ Surgery and ${ }^{2}$ Medicine, University of North Carolina, Chapel Hill, North Carolina. 
the majority of the patients (recommendation ++++ , strong evidence). ${ }^{13}$

Previously, LHM has been recognized as a highly effective long-term treatment for achalasia patients ( $>90 \%$ dysphagia relief $\left.^{21}\right) .^{3,13,17,22}$ However, to prevent postoperative GER, an antireflux procedure should be performed in addition to myotomy. ${ }^{23,24}$ This lesson was learned during the evolution of minimally invasive procedures for achalasia, shifting from the thoracoscopic to the laparoscopic approach with the addition of a fundoplication. ${ }^{25,26}$ For example, Richards et al. reported $47.6 \%$ pathologic reflux with median DeMeester score of 31.5 (range 3-270) at 6-month follow-up after LHM alone, but only $9 \%$ after adding a partial anterior Dor fundoplication. ${ }^{27}$ Other studies have confirmed the value of a partial fundoplication after LHM. ${ }^{28,29}$

This article reviews the pros and cons of the different types of fundoplications after LHM.

\section{Fundoplication: Yes or No}

In 1956 , Nissen proposed the $360^{\circ}$ fundoplication to control reflux in GER patients. ${ }^{30}$ In 1962, Dor described an anterior partial fundoplication procedure technique de HellerNissen modifiee covering the exposed mucosa at the area of the myotomy. ${ }^{31}$ In 1963 , A. Toupet described the folding and anchoring of the gastric fundus posterior to the esophagus. ${ }^{32}$ Both the Dor and the Toupet procedures were proposed to limit GER while still allowing relief of dysphagia.

Although there was a trend toward minimally invasive operations for Heller myotomy, the value of adding a fundoplication was still uncertain. On one side of the debate, several authors believed that it was not required to perform an antireflux procedure after LHM, as it would cause recurrence of dysphagia due to lack of peristalsis. ${ }^{33,34}$ Others were proponents of a routine fundoplication after LHM.

Falkenback et al. ran a prospective randomized trial in 20 open Heller myotomy patients comparing those with and without floppy Nissen fundoplication. ${ }^{35}$ At $>3$ years followup, the authors found pathologic GER by $\mathrm{pH}$ testing in $13.1 \%$ of the no fundoplication group and in $0.15 \%$ only of the fundoplication group.

In 2004, Richards et al., in a prospective randomized double-blind trial, proved the superiority of LHM and anterior partial fundoplication versus LHM alone regarding postoperative GER, by objective $\mathrm{pH}$ evaluation. ${ }^{27}$ In addition, a large meta-analysis including >3000 patients after LHM found a higher rate of postoperative GER when LHM was performed without an antireflux procedure (32\% versus $9 \%) .{ }^{18}$ On the basis of these data, LHM plus partial fundoplication is considered in most centers worldwide as the gold standard modality for the approach to achalasia.

\section{LHM and Fundoplication: Total or Partial?}

Among those who were proponents of a fundoplication after LHM for achalasia, there was disagreement over the type of fundoplication. Since a floppy total fundoplication has been shown to be effective in cases of weak esophageal peristalsis, ${ }^{36}$ some authors initially tried to apply total fundoplication after LHM. ${ }^{35,37}$ However, because of the lack of peristalsis in achalasia patients, others argued that a $360^{\circ}$ fundoplication would increase the outflow resistance, impeding esophageal emptying and causing persistent or recurrent dysphagia, ${ }^{29,38}$ and pointed out that a partial fundoplication compares favorably with a total fundoplication for GER control, while causing less postoperative dysphagia. ${ }^{39}$

Case series are conflicting. Topart et al. ${ }^{40}$ found at a 10 -year follow-up after LHM and total fundoplication that most of the patients $(82 \%)$ have recurrence of symptoms, whereas Rossetti et al. ${ }^{41}$ described excellent dysphagia alleviation in $>90 \%$ of patients, and no GER at mean follow-up of 83 months.

Di Martino et al. ${ }^{42}$ performed a retrospective comparative study between well-matched patients who had anterior versus posterior fundoplication after LHM. After 2-year follow-up, they reported similar GER and dysphagia symptom scores, with lower GEJ pressures and higher distal esophageal acid after partial fundoplication.

Rebecchi et al. ran a prospective randomized trial analyzing the difference between anterior partial fundoplication to $360^{\circ}$ fundoplication after LHM. ${ }^{39}$ They enrolled 144 patients (72 Dor and 72 Nissen). At a 5-year follow-up, the incidence of GER was low and similar in the two groups, but $15 \%$ of patients after Nissen fundoplication had dysphagia compared with only $2.8 \%$ after Dor fundoplication.

There is vast literature that confirms similar findings, showing that LHM with either anterior or posterior partial fundoplication is a highly effective procedure controlling dysphagia, developing minimum rates of postoperative GER, and improving QoL in most of the patients. ${ }^{43,44}$ In addition, a recent study details how several early proponents of total fundoplication have altered their recommendations after recognizing that late esophageal decompensation may cause recurrence of dysphagia. ${ }^{38}$

Therefore, today a $360^{\circ}$ fundoplication is discouraged for patients with esophageal achalasia after LHM because it is associated with higher postoperative dysphagia rates. ${ }^{3,13}$ As stated by the 2018 International Society for Diseases of the Esophagus guidelines, ${ }^{3}$ an LHM with partial wrap (either anterior or posterior) should be the chosen technique for patients with achalasia, as it achieves the main goal of relieving dysphagia while preventing GER in most patients

\section{LHM and Fundoplication: Anterior or Posterior?}

What type of partial fundoplication to use is still unclear. To date, two randomized controlled trials and a meta-analysis have addressed this question.

Rawlings et al. ${ }^{43}$ ran a multicenter prospective trial, comparing patients undergoing either an anterior $(n=36)$ or posterior $(n=24)$ partial wrap after LHM. At 1-year followup, they found a minimum difference regarding symptoms control between the two groups, whereas 24-hour $\mathrm{pH}$ monitoring showed similar rates of postoperative reflux.

Kumagai et al. $^{45}$ found no significant difference of postoperative GER by $\mathrm{pH}$ testing and Eckardt scores at 1-year follow-up among patients who had a Dor $(n=20)$ or a Toupet $(n=22)$ fundoplication after LHM.

Results from a meta-analysis that assessed both procedures after LHM, in $~ 3000$ patients, ${ }^{46}$ showed similar effectiveness as antireflux procedure, but a significant lower rate of reintervention after the partial posterior wrap for postoperative dysphagia.

Overall, some surgeons prefer the partial posterior fundoplication because it keeps the edges of the myotomy separated, thus reducing the probability of recurrent 


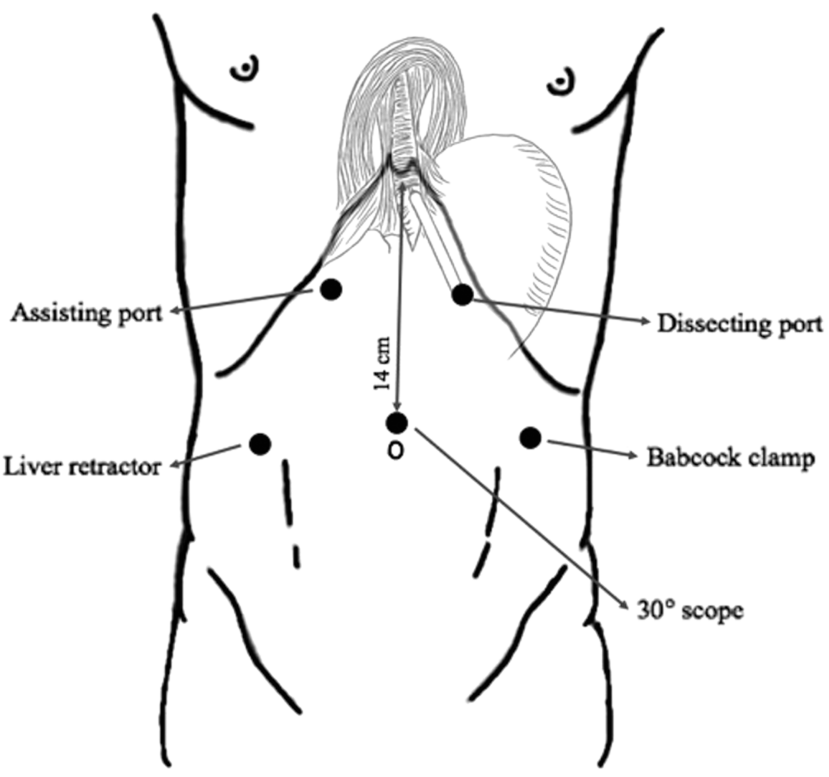

FIG. 1. Positions of trocars for Heller myotomy.

dysphagia. ${ }^{47,48}$ Other experts suggest that the use of a partial anterior Dor fundoplication allows limited hiatal dissection avoiding disruption of anatomic structures that help controlling GER, diminishing the probability of injury of the posterior vagus nerve, and allowing coverage of the exposed mucosa. $29,49,50$

\section{Technical Recommendations}

\section{LHM with Toupet fundoplication}

Pneumoperitoneum is achieved, and a five-port technique is used (Fig. 1). Reverse Trendelenburg position is used. A liver retractor is inserted through the inferior right trocar. The gastrohepatic omentum is opened and the phrenoesophageal membrane is divided, taking care of the anterior vagus nerve. The greater curvature of the stomach is mobilized, and the esophagus and both vagus nerves are surrounded with a Penrose drain. With countertraction on the GEJ, the dissection is continued liberally into the mediastinum until the GEJ remains in the abdominal cavity without tension.

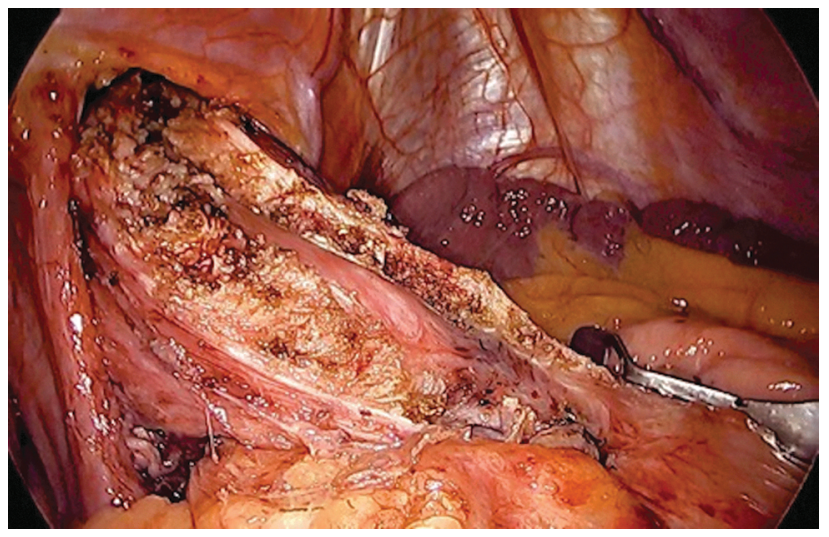

FIG. 2. Heller myotomy.

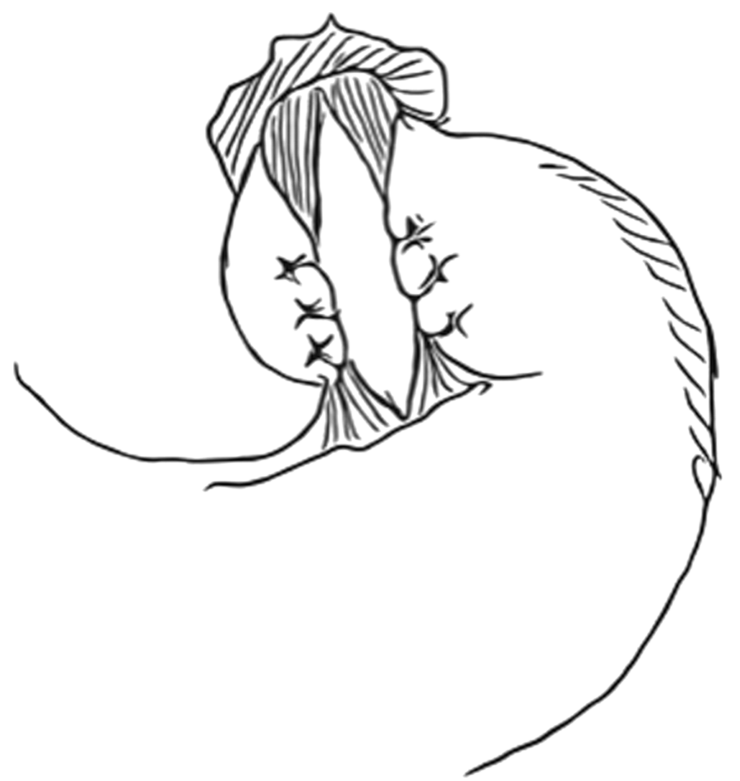

FIG. 3. Posterior $\sim 240^{\circ}$ Toupet fundoplication.

Before creating the wrap, the GEJ fat pad is reflected or resected, and then a longitudinal seromuscular incision is made starting either just below or just above the GEJ. Longitudinal and circumferential muscle fibers are divided until the mucosa is visualized. The myotomy is extended for
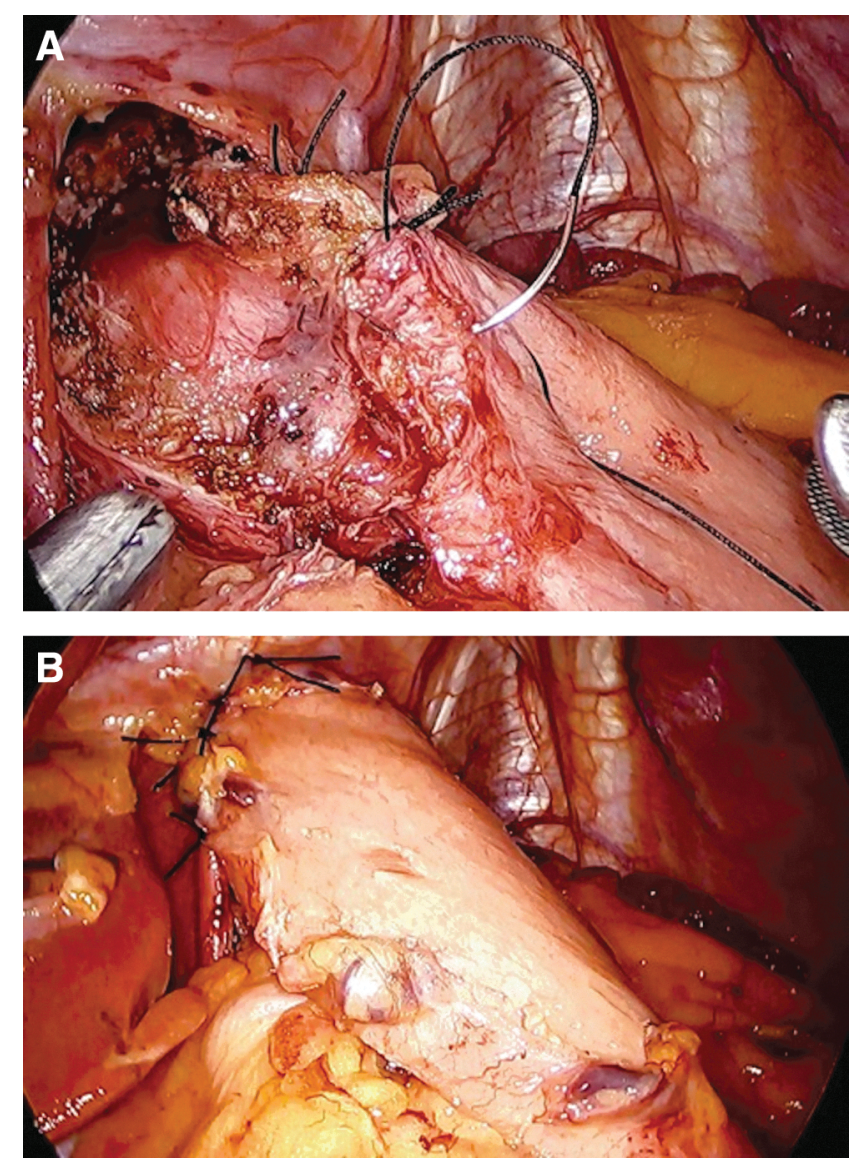

FIG. 4. (A) First row of sutures for anterior $180^{\circ}$ Dor fundoplication. (B) Anterior $180^{\circ}$ Dor fundoplication. 
$6 \mathrm{~cm}$ above the GEJ and $2-3 \mathrm{~cm}$ distally onto the gastric wall (Fig. 2), avoiding the anterior vagus nerve. One possible risk of Heller myotomy is esophagogastric mucosal perforation. Patients previously treated for achalasia, by either PD or botulinum toxin, are at greater risk. Intraoperative injuries are repaired immediately with absorbable sutures, usually without additional morbidity. Many surgeons routinely assess mucosal integrity at the completion of the myotomy by instillation of methylene blue or air. If a repair is needed, an anterior (Dor) fundoplication is more appropriate as it covers the damaged mucosa.

Hiatoplasty is performed posterior to the esophagus with heavy permanent sutures to close the esophageal hiatus but avoiding angulation of the esophagus. Then, the gastric fundus is passed through the retroesophageal window, and a $\sim 220-240^{\circ}$ partial posterior fundoplication (Fig. 3) is created, anchoring the fundus to the edges of the myotomy to keep them separated.

\section{LHM with Dor fundoplication}

Myotomy is performed as previously described. However, no posterior dissection is necessary, and often there is no need to perform a hiatoplasty. The lack of posterior dissection avoids injury to the posterior vagus nerve.

After completion of the myotomy, the gastric fundus is mobilized by taking down the short gastric vessels and an anterior $180^{\circ}$ fundoplication (Dor) is made over the esophagus. The fundus is anchored by two rows of stitches on each side of the esophagus lateral to the exposed mucosa (Fig. 4a). The first stitch of the left row is performed in a triangular manner between the fundus, esophagus, and left pillar. Two or three more stitches are then used to secure the fundus to the esophagus. The gastric fundus is then folded over the myotomy, and the greater curvature is anchored to the right pillar with three stitches. Lastly, two apical stitches are added between the fundoplication and the rim of the esophageal hiatus to avoid tension on the repair (Fig. 4b).

\section{Conclusions}

In conclusion, the body of scientific evidence supports the use of a partial wrap after LHM for patients with achalasia. The lesson learned over many years should be kept in mind as today peroral endoscopic myotomy is more and more frequently used, exposing patients to the life-long risk of GER.

As the literature fails to show any significant difference between Dor and Toupet fundoplications, surgeons should decide to perform an anterior or a posterior wrap based on their own experience and preference. ${ }^{28}$

\section{Disclosure Statement}

No competing financial interests exist.

\section{References}

1. Boeckxstaens GE, Zaninotto G, Richter JE. Achalasia. Lancet 2014;383:83-93.

2. Samo S, Carlson DA, Gregory DL, Gawel SH, Pandolfino JE, Kahrilas PJ. Incidence and Prevalence of Achalasia in Central Chicago, 2004-2014, Since the Widespread use of High-Resolution Manometry. Clin Gastroenterol Hepatol 2017;15:366-373.
3. Zaninotto G, Bennett C, Boeckxstaens G, et al. The 2018 ISDE achalasia guidelines. Dis Esophagus 2018;31:1-29.

4. Enestvedt BK, J. Lucas Williams B, Sonnenberg A. Epidemiology and practice patterns of achalasia in a large multi-center database. Aliment Pharmacol Ther 2013;33: $1-9$.

5. Molena D, Yang SC. Surgical management of end-stage achalasia. Semin Thorac Cardiovasc Surg 2012;24:19-26.

6. Schlottmann F, Patti MG. Esophageal achalasia: Current diagnosis and treatment. Expert Rev Gastroenterol Hepatol 2018;12:711-721.

7. Pressman A, Behar J. Etiology and pathogenesis of idiopathic achalasia. J Clin Gastroenterol 2017;51:195-202.

8. Gockel I, Bohl JRE, Doostkam S, Eckardt VF, Junginger T. Spectrum of histopathologic findings in patients with achalasia reflects different etiologies. J Gastroenterol Hepatol 2006;21:727-733.

9. Goyal RK, Chaudhury A. Pathogenesis of achalasia: Lessons from mutant mice. Gastroenterology 2010;139:10861090 .

10. Schlottmann F, Herbella F, Allaix ME, Patti MG. Modern management of esophageal achalasia: From pathophysiology to treatment. Curr Probl Surg 2018;55:10-37.

11. Leeuwenburgh I, Scholten P, Alderliesten J, et al. Longterm esophageal cancer risk in patients with primary achalasia: A prospective study. Am J Gastroenterol 2010; 105:2144-2149.

12. Tustumi F, Bernardo WM, da Rocha JRM, et al. Esophageal achalasia: A risk factor for carcinoma. A systematic review and meta-analysis. Dis Esophagus 2017;30:1-8.

13. Stefanidis D, Richardson W, Farrell TM, Kohn GP, Augenstein V, Fanelli RD. SAGES guidelines for the surgical treatment of esophageal achalasia. Surg Endosc Other Interv Tech 2012;26:296-311.

14. Yamaguchi D, Tsuruoka N, Sakata Y, Shimoda R, Fujimoto K, Iwakiri R. Safety and efficacy of botulinum toxin injection therapy for esophageal achalasia in Japan. J Clin Biochem Nutr 2015;57:239-243.

15. Inoue $H$, Sato $H$, Ikeda $H$, et al. Per-oral endoscopic myotomy: A series of 500 patients. J Am Coll Surg 2015; 221:256-264.

16. Lopushinsky SR, Urbach DR. Pneumatic dilatation and surgical myotomy for achalasia. J Am Med Assoc 2006; 296:2227-2233.

17. Weber CE, Davis CS, Kramer HJ, Gibbs JT, Robles L, Fisichella PM. Medium and long-term outcomes after pneumatic dilation or laparoscopic heller myotomy for achalasia: A meta-analysis. Surg Laparosc Endosc Percutaneous Tech 2012;22:289-296.

18. Campos GM, Vittinghoff E, Rabl C, et al. Endoscopic and surgical treatments for achalasia: A systematic review and meta-analysis. Ann Surg 2009;249:45-57.

19. Yaghoobi M, Mayrand S, Martel M, Roshan-Afshar I, Bijarchi R, Barkun A. Laparoscopic Heller's myotomy versus pneumatic dilation in the treatment of idiopathic achalasia: A meta-analysis of randomized, controlled trials. Gastrointest Endosc 2013;78:468-475.

20. Patti MG, Andolfi C, Bowers SP, Soper NJ. POEM vs laparoscopic Heller myotomy and fundoplication: Which is now the gold standard for treatment of achalasia? J Gastrointest Surg 2017;21:207-214.

21. Zaninotto G, Costantini M, Rizzetto C, et al. Four hundred laparoscopic myotomies for esophageal achalasia a single centre experience. Ann Surg 2008;248:986-993. 
22. SAGES. Quality of life outcomes after heller myotomy for achalasia comparing Dor and Toupet fundoplications. www .sages.org/meetings/annual-meeting/abstracts-archive/qualityof-life-outcomes-after-heller-myotomy-for-achalasia-compar ing-dor-and-toupet-fundoplications (last accessed January 8, 2019).

23. Wei MT, He YZ, Deng XB, et al. Is Dor fundoplication optimum after laparoscopic Heller myotomy for achalasia? A meta-analysis. World J Gastroenterol 2013;19:78047812.

24. Andolfi C, Baffy G, Fisichella PM. Whose patient is it? The path to multidisciplinary management of achalasia. J Surg Res 2018;228:8-13.

25. Pellegrini C, Wetter LA, Patti M, et al. Thoracoscopic esophagomyotomy. Initial experience with a new approach for the treatment of achalasia. Ann Surg 1992;216:291296; discussion 296-299.

26. Patti MG, Pellegrini CA, Horgan S, et al. Minimally invasive surgery for achalasia: An 8-year experience with 168 patients. Ann Surg 1999;230:587-593; discussion 593594.

27. Richards WO, Torquati A, Holzman MD, et al. Heller myotomy versus heller myotomy with dor fundoplication for achalasia: A prospective randomized double-blind clinical trial. Ann Surg 2004;240:405-415.

28. Rebecchi F, Allaix ME, Schlottmann F, Patti MG MM. Laparoscopic Heller myotomy and fundoplication: What is the evidence? Am Surg 2018;84:481-489.

29. Tomasko JM, Augustin T, Tran TT, Haluck RS, Rogers AM, Lyn-Sue JR. Quality of life comparing Dor and Toupet after Heller myotomy for achalasia. JSLS J Soc Laparoendosc Surg 2014;18:e2014.00191.

30. Nissen R. [A simple operation for control of reflux esophagitis]. Schweiz Med Wochenschr 1956;86(Suppl 20): 590-592.

31. Dor J, Humbert P, Dor V, Figarella J. The importance of the modified Nissen technique for reflux control after Heller extramucosal cardiomyotomy (in French). Mem Acad Chir 1962;88:877-883.

32. Toupet A. Technique of esophago-gastroplasty with phrenogastropexy used in radical treatment of hiatal hernias as a supplement to Heller's operation in cardiospasms (in French). Acad Chir 1963;89:394-399.

33. Wang PC, Sharp KW, Holzman MD, Clements RH, Holcomb GW, Richards WO. The outcome of laparoscopic Heller myotomy without antireflux procedure in patients with achalasia. Am Surg 1998;64:515-520; discussion 521.

34. Diamantis T, Pikoulis E, Felekouras E, et al. Laparoscopic esophagomyotomy for achalasia without a complementary antireflux procedure. J Laparoendosc Adv Surg Tech 2006; 16:345-349.

35. Falkenback D, Johansson J, Öberg S, et al. Heller's esophagomyotomy with or without a $360^{\circ}$ floppy Nissen fundoplication for achalasia. Long-term results from a prospective randomized study. Dis Esophagus. 2003;16: 284-290.

36. Patti MG, Robinson T, Galvani C, et al. Total fundoplication is superior to partial fundoplication even when esophageal peristalsis is weak. J Am Coll Surg 2004;198: 863-870.

37. Donahue PE, Schlesinger PK, Sluss KF, et al. Esophagocardiomyotomy-Floppy Nissen fundoplication effectively treats achalasia without causing esophageal obstruction. Surgery 1994;116:719-724; discussion 724 725.

38. Patti MG, Herbella FA. Fundoplication after laparoscopic Heller myotomy for esophageal achalasia: What type? J Gastrointest Surg 2010;14:1453-1458.

39. Rebecchi F, Giaccone C, Farinella E, Campaci R, Morino M. Randomized controlled trial of laparoscopic heller myotomy plus dor fundoplication versus nissen fundoplication for achalasia long-term results. Ann Surg 2008;248: 1023-1029.

40. Topart P, Deschamps C, Taillefer R, Duranceau A. Longterm effect of total fundoplication on the myotomized esophagus. Ann Thorac Surg 1992;54:1046-1052.

41. Rossetti G, Brusciano L, Amato G, et al. A total fundoplication is not an obstacle to esophageal emptying after heller myotomy for achalasia: Results of a long-term follow up. Ann Surg 2005;241:614-621.

42. Di Martino N, Brillantino A, Monaco L, et al. Laparoscopic calibrated total vs partial fundoplication following heller myotomy for oesophageal achalasia. World J Gastroenterol 2011;17:3431-3440.

43. Rawlings A, Soper NJ, Oelschlager B, et al. Laparoscopic Dor versus Toupet fundoplication following Heller myotomy for achalasia: Results of a multicenter, prospective, randomized-controlled trial. Surg Endosc Other Interv Tech 2012;26:18-26.

44. Ortiz A, De Haro LFM, Parrilla P, et al. Very long-term objective evaluation of Heller myotomy plus posterior partial fundoplication in patients with achalasia of the cardia. Ann Surg 2008;247:258-264.

45. Kumagai K, Kjellin A, Tsai JA, et al. Toupet versus Dor as a procedure to prevent reflux after cardiomyotomy for achalasia: Results of a randomised clinical trial. Int J Surg 2014;12:673-680.

46. Kurian AA, Bhayani N, Sharata A, Reavis K, Dunst CM, Swanström LL. Partial anterior vs partial posterior fundoplication following transabdominal esophagocardiomyotomy for achalasia of the esophagus: Meta-regression of objective postoperative gastroesophageal reflux and dysphagia. JAMA Surg 2013;148:85-90.

47. Hunter JG, Trus TL, Branum GD, Waring JP. Laparoscopic Heller myotomy and fundoplication for achalasia. Ann Surg 1997;225:655-664; discussion 664-665.

48. Tatum RP, Pellegrini CA. How i do it: Laparoscopic Heller myotomy with Toupet fundoplication for achalasia. J Gastrointest Surg 2009;13:1120-1124.

49. Patti MG, Fisichella PM. Laparoscopic heller myotomy and dor fundoplication for esophageal achalasia. How i do it. J Gastrointest Surg 2008;12:764-766.

50. Simić AP, Radovanović NS, Skrobić OM, Ražnatović ZJ, Peško PM. Significance of limited hiatal dissection in surgery for achalasia. J Gastrointest Surg 2010;14:587-593.

Address correspondence to: Marco G. Patti, MD, FACS Department of Surgery University of North Carolina 4030 Burnett Womack Building 101 Manning Drive, CB 7081 Chapel Hill, NC 27599-7081

E-mail: marco_patti@med.unc.edu 